\title{
Study on the Effect of China's Interest Rate Policies on the Return of Stock Market
}

\author{
Xin $\operatorname{Lin}^{1}$, Yizhou Tang ${ }^{1, \text { a }}$ \\ ${ }^{1}$ School of Economics and Management, Tongji University, Shanghai 201804, China; \\ atyzlunwen@163.com
}

Keywords: Interest rate policy, rate of return, China's stock market, nonparametric tests, event study

\begin{abstract}
Analyzing the impact of the interest rate policies performed by the China's central bank on the rate of return of China's stock market, this paper intends to test the effectiveness of the monetary policies. Based on the method of event study and nonparametric test, 24 events of interest rate adjustment from 1993 to 2014 are studied. The results demonstrate that the interest rate policies have no systematic and significant effect on the return rate of China's stock market, which also indicate that the mechanism of how monetary policy and the stock market affect each other is not perfect.
\end{abstract}

\section{Introduction}

Interest rate policies will absolutely have an effect the money demand and supply on capital market. The monetary policies of central bank, therefore, draw numerous attentions of the whole society, which is of value in researching the mechanism of capital market.

Many studies have been reported on efficiencies of monetary (or interest-rate) policy and stock market, as well as on the interaction between the two. Bernanke and Kuttner (2004) studied the effect of changes in monetary policy on stock price using a method by Ammer (1993), and measured both the mean effect of policy changes on stock market and the economic source of such a reaction. They concluded that an unexpected descending of the federal funds rate by 25 points could lead to a rise of the market index by $1 \%$, and found that the fluctuation of stock price could be largely explained by the effect of unexpected monetary policies on expected excess return. By using a new estimator based on data heteroscedasticity, Roberto and Brian (2002) estimated how-and to what degree-the changes in asset price were reacted to the changes in monetary policy. Their conclusions suggested that asset price changes were resulted from the variance of policy shock as well as from the semi-annual monetary policy by the chairman of the Federal Reserve. Zhou Wenli and Wang Xi (2011) investigated the effects of both expected and unexpected monetary policies on Shenzhen and Shanghai stock markets by using the prediction method of ARIMA. Their results showed that the stock yield was significantly related to the latter but, basically, had no relation with the former. On the basis of previous studies, and by using the interest-rate policies of People's Bank of China implemented from 1993 to 2014 as the data, this article has discussed the effect mechanism between interest-rate policy and Chinese A-share market from the perspective of event-study analysis. Our results can be used as a reference for judging whether the A-share market is effective and whether the effect mechanism, say, “interest-rate policy-macro economy-A-share market”, exists or not.

The following structure of this article is divided into three parts. The first is a brief introduction to methods used in this study, including the explanation of sample selection. Second, the method of event-study analysis is employed to research both the interest-rate policy and the prices on A-share market, with results being obtained and tested as well. The final part is a summary based on the above empirical results.

\section{Methodology}

Introduction to the Methods. The major method use in this article is "event-study", in which, event is the cause for abnormal return. Here, it is the interest-rate decision made by People's Bank of China. 
Samples' normal return is estimated using the method of mean-shift, and the average rate of return of a variable of the study object is also calculated during the estimation period. The rate is then taken as the average return rate during the event period. The abnormal return can be calculated via the normal return, as follows:

$$
A_{i t}=R_{i t}-N_{i t}
$$

Where $N_{i t}$ is the estimated normal return; $R_{i t}$ is real return, and $A_{i t}$ is abnormal return.

Normal return is estimated by CAPM model:

$$
N_{i t}=\alpha_{i}+\beta_{i} \times R_{m}
$$

Here, estimated normal return can be computed by market return $R_{m}$. And $\alpha_{i}, \beta_{i}$ is parameters.

In this study, the accumulative abnormal return (CAR) is taken as the reference variable, namely, the sum of the average abnormal returns of all the samples during the event period. It can be calculated by:

$$
C A R=\sum_{t=t_{1}}^{t_{2}}\left(\frac{1}{N} \sum_{i=1}^{N} A_{i t}\right)
$$

Where, $A_{i t}$ is the abnormal return rate of sample $\mathrm{i}$ at the moment of $\mathrm{t}$; $\mathrm{N}$ is the number of samples; $t_{1}$ and $t_{2}$ are the starting and ending time of the event period, respectively.

Finally, the sign test, one of nonparametric tests, is used, the basis of which is the sign of the abnormal return, which requires that securities' abnormal returns (or CARs) shall be independent with each other. The null hypothesis of this method is that: the ratio of positive abnormal returns is 0.5 .

$$
Z_{1}=\left(\frac{N^{+}}{N}-0.5\right) \frac{N^{1 / 2}}{0.5}
$$

Where, $N^{+}$is the number of positive abnormal returns (or CARs) that have been observed, $Z_{1}$ is a standard normal distribution.

Sample Selection. In this article, indexes of Shenzhen and Shanghai stock markets when the monetary policy, say, the adjustment of the benchmark interest rate implemented by People's Bank of China during 1993-2014 (22 years in total), are taken as our study samples. During the 22 years, 32 times of interest-rate decisions have been made by the Bank [11]. Dates and amplitudes of the adjustment are listed in Figure 1 and 2.

In the 22 years, 17 times of decision have been made by the Bank to raise the interest-rate, while 15 times to cut the interest-rate. As can be found, interest-rate policies have been implemented periodically. In other words, interest-rate policies during a specific economic cycle tend to be implemented along the same direction, without intersectional and nonsystematic policies to raise and cut the interest-rate at the same time. For selecting event windows, the dates, on which the same directional interest-rate policies were implemented, were close, and, therefore, can be seen as different stages of a same event. Hence, criteria for defining event as well as for dividing estimation period and event period are:

(1) Events that are happened within 30 natural days are seen as different stages of a same event, while events that are happened not within 30 natural days are seen as different events;

(2) Event period is the period containing 30 trading days before the event and 30 trading days after the event. Proper measures can be taken for special cases.

(3) Estimation period is the period containing 90 or 120 days before the event period. Proper measures can be taken for special cases.

Based on the above criteria, the policies to raise interest-rate implemented on July 20, 2007, August 22, 2007 and September 15, 2007, are taken as one event. The 5 policies to cut interest-rate implemented during the whole year of 2008 are taken as one event. The 2 policies to cut interest-rate implemented during 2012 are taken as one event. Besides, the long-term impact of each event on 
market index has not been taken into account. Therefore, there are 25 events in total, of which, 14 events are policies to raise interest-rate and 11 events to cut interest-rate.

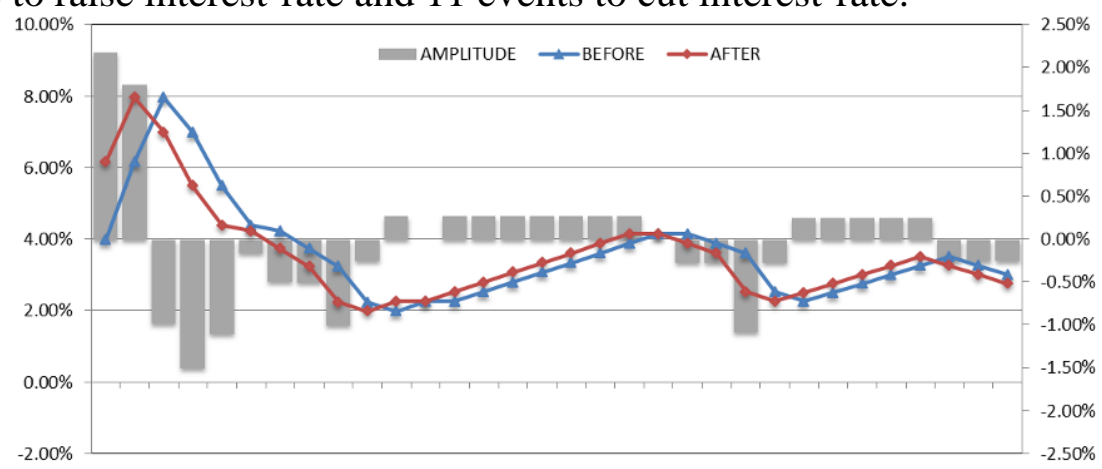

Fig. 1 Adjustment of benchmark deposit rate from 1993 to 2014

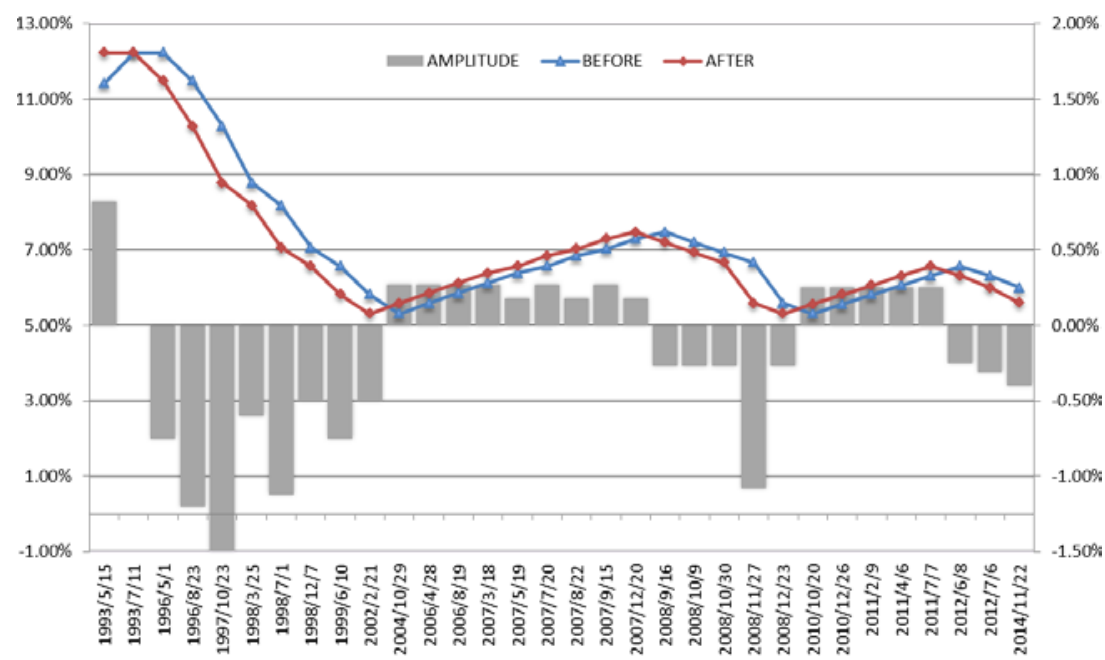

Fig. 2 Adjustment of benchmark loan rate from 1993 to 2014

\section{Empirical Study}

After the samples being selected and each period being defined, normal returns are then calculated by using the method of mean-shift, and the value of CAR corresponding to each event period has been calculated as well, as shown in Figure 3.

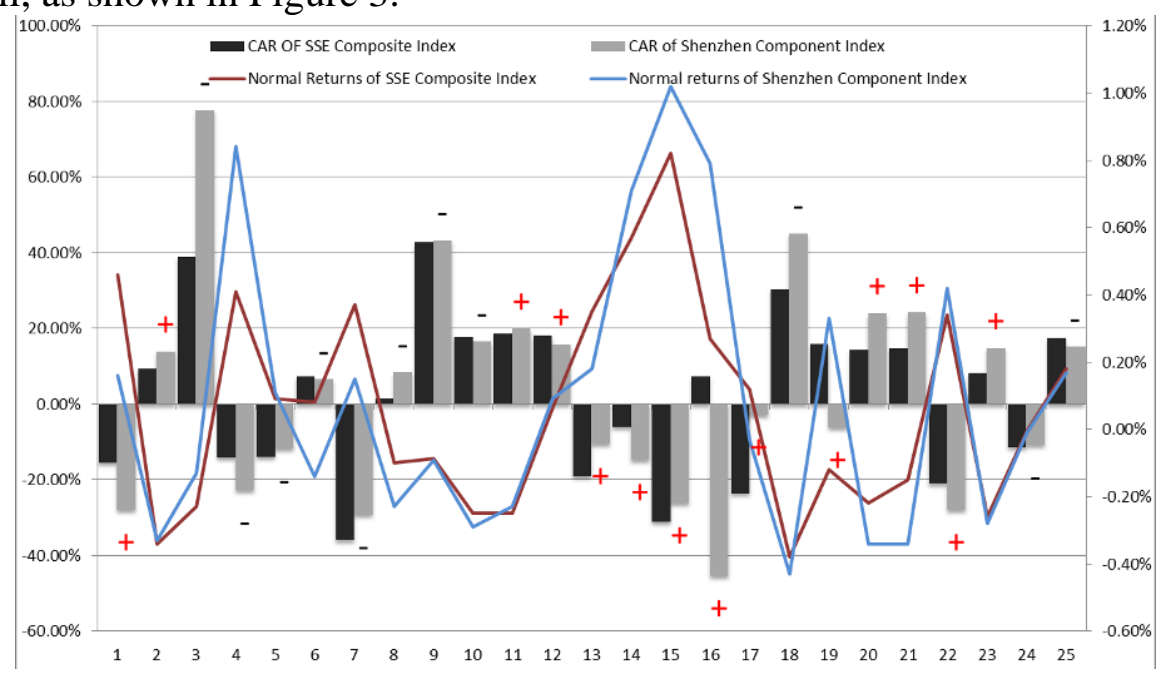

Fig. 3 Normal returns \& CAR of each event period

A same direction can be seen in the reactions of Shenzhen and Shanghai stock markets to interest-rate policies, namely, CARs on the two markets were changing basically along the same direction, which, from a different perspective, reflects the internal relation between the two markets. 
To precisely express the effect of interest-rate policies on stock market, the reactions of the two markets to policies to raise and cut interest-rate will be tested, respectively. For Shanghai stock market, among the 14 events of raising the interest-rate, there are 8 events showing positive CARs, so the value of $\mathrm{Z}$ is $Z_{1}=0.535$, which is a standard normal distribution. Therefore, this is a two-sided test, and the corresponding $p$ value is 0.5962 , which is far from the level of $5 \%$, i.e., the null hypothesis is not rejected. Table 1 lists the $\mathrm{Z}$ and $\mathrm{p}$ values for both policies to raise and cut interest-rate on the two markets.

Table 1 Policies effect on the two markets

\begin{tabular}{|c|c|c|c|c|c|c|c|}
\hline \multicolumn{4}{|c|}{ Shanghai } & \multicolumn{4}{|c|}{ Shenzhen } \\
\hline $\begin{array}{c}\text { Z-value of } \\
\text { raise }\end{array}$ & $\begin{array}{c}\text { p-value of } \\
\text { raise }\end{array}$ & $\begin{array}{c}\text { Z-value of } \\
\text { cut }\end{array}$ & $\begin{array}{c}\text { p-value of } \\
\text { cut }\end{array}$ & $\begin{array}{c}\text { Z-value of } \\
\text { raise }\end{array}$ & $\begin{array}{c}\text { p-value of } \\
\text { raise }\end{array}$ & $\begin{array}{c}\text { Z-value of } \\
\text { cut }\end{array}$ & $\begin{array}{c}\text { p-value of } \\
\text { cut }\end{array}$ \\
\hline 0.535 & 0.5962 & 0.6325 & 0.5286 & -0.5345 & 0.5962 & 0.6325 & 0.5286 \\
\hline
\end{tabular}

Test results show a high similarity in the reactions of Shenzhen and Shanghai stock markets to policies to raise and cut interest-rate, and in both cases the null hypothesis not rejected

The above empirical results suggest that the two stock markets tend to react along a same direction. The null hypothesis cannot be rejected because p value is far larger than the acceptable level of 5\%. In other words, the ratio of positive CARs to negative CARs tends to be $1: 1$, which indicates that interest-rate policies do not have significant impact on stock market and the stock index may change at random.

\section{Summary}

Empirical results show that interest-rate policies have no significant impact on stock market and the stock index may change at random. This is an important conclusion, for it differs from people's common sense: "raising interest-rate will decrease liquidity and the stock index goes down; cutting interest-rate will increase liquidity and the stock index goes up". There must be problem(s) in one or two links of the effect mechanism of "interest-rate policy-macro economy-A-share market", which fails the expected effect of the interest-rate policies on A-share market, suggesting that this market is not efficient by far. To some degree, this empirical result reflects well that Chinese capital market is immature by now.

Based on the results obtained, the fact that China stock market is still at the immature stage though it experience about 20 years of development. It is imperative for the policymaker to carry out regulations and legislations to protect the interest of small investors.

There are also limitations in this study. For historical reasons, for example, the size of the collected event samples is relatively small; the event period and estimation period for some event are shorten for special reasons, and; results of the study can be influenced by different period lengths, normal return models and test methods, etc. These problems need to be solved in further studies.

\section{References}

[1] Roberto Rigobon, Brian Sack. Measuring the reaction of monetary policy to the stock market[DB/OL]. NBER Working Paper No.8350, 2001.

[2] Douglas K. Pearce, V. Vance Roley. Stock prices and economic news[DB/OL]. NBER Working Paper No.1296, 1984.

[3] Roberto Rigobon, Brian Sack. The impact of monetary policy on asset prices[DB/OL]. NBER Working Paper No.8794, 2002.

[4] Ben S. Bernanke, Kenneth N. Kuttner. What explains the stock market's reaction to federal reserve policy[DB/OL]. NBER Working Paper No.10402, 2004.

[5] Michael D. Bordo, Michael J. Dueker, David C. Wheelock. Inflation, monetary policy and stock market conditions[DB/OL].NBER Working Paper No. 140192008. 
[6] Airaudo, M, Nistico, S and Zanna, LF. Learning, Monetary Policy, and Asset Prices. Journal of Money Credit and Banking. Vol. 47 (2015) No. 7, pp. 1273-1307.

[7] Maio, P and Philip, D. Macro variables and the components of stock returns. Journal of Empirical Finance. Vol. 33 (2015), pp. 287-308.

[8] Lv, X, Dong, WJ and Fang, F. The Asymmetric Effects of Official Interest Rate Changes on China's Stock Market During Different Market Regimes. Emerging Markets Finance and Trade. Vol. 51 (2015) No. 4, pp. 826-841.

[9] Belke, A and Beckmann, J. Monetary policy and stock prices - Cross-country evidence from cointegrated VAR models. Journal of Banking \& Finance. Vol. 54 (2015), pp. 254-265.

[10] Pennings, S, Ramayandi, A and Tang, HC. The impact of monetary policy on financial markets in small open economies: More or less effective during the global financial crisis?. Journal of Macroeconomics. Vol. 44 (2015), pp.60-70.

[11] Information on http://www.pbc.gov.cn/ 